Sergio Peña Neira*

\title{
Las fuentes de Derecho Internacional Público, diversidad de tribunales internacionales y generación del Estado de Derecho Internacional Público ${ }^{1}$
}

\section{The sources of public international law, diversity of international courts and generation Public International Law state}

\begin{abstract}
Resumen
El valor de las Fuentes de Derecho Internacional Público o se ha relativizado o absolutizado en razón del aumento y reconducción de expresiones normativo-jurídico internacionales. Esto tiene su origen en el Derecho internacional general y en el Derecho Internacional Público de los tratados. Las fuentes en el Orden Jurídico Internacional se expresan cuando las normas jurídicas conllevan la obligación de aplicación (supuesta ratificación o aplicación directa) y, a su vez, la ausencia de aplicación (supuesta la misma) acarrea responsabilidad jurídica internacional. Lo veremos en dos autores, Bello y Álvarez. Son interpretadas y aplicadas a nivel nacional debido a la unidad del Orden jurídico como expresión de un "Estado de Derecho Internacional Público".
\end{abstract}

\footnotetext{
* Profesor en la Escuela de Derecho de la Universidad Bernardo O'Higgins (Teoría del Derecho) y profesor invitado en la Universidad de Chile. Licenciado y Magister en Relaciones internacionales y Europeas, sergio.penaneira@ gmail.com.
} 


\title{
Palabras clave
}

Estado de Derecho internacional, Fuentes, Orden Jurídico, Norma Jurídica

\begin{abstract}
The value of the sources of international (public) law or is relative or absolute based on the growing and reformulation of international juridical norms. This has as source the general international (public) law and the (public) international law of treaties. The sources of the international juridical order expressed their selves when the juridical norms include the obligation of application (based upon ratification or direct application) and, at the same time, the absence of the application (based upon itself) produces international juridical responsibility. We will study two authors, Bello and Alvarez. The international legal rules will be interpreted and applied at the national level due to the unity of the juridical Order, as expression of an "public international rule of law).
\end{abstract}

\section{Key words}

International rule of law, Rechtstaat, Sources, Juridical Order, Juridical Norm

\section{I.- Introducción}

Todo Orden Jurídico posee "orígenes", "causas eficientes" de las normas jurídicas que la regulan, es decir, normas jurídicas que crean otras normas jurídicas o que generan directamente, las mismas, derechos y obligaciones ${ }^{2}$.

El "Estado de Derecho internacional" es el conjunto de normas jurídicas positivizadas o no y a las que se encuentran sometidas las relaciones internacionales entre sujetos y objetos del Derecho Internacional Público sometiendo al Poder de manera general y abstracta a través de las mismas normas jurídicas internacionales.

El "Estado de Derecho Internacional Público", así definido, tiene "fuentes" de su ordenación. Este concepto pasa desde el ámbito político al jurídico y es ahí donde se efectúa un análisis por aproximación a lo que constituiría su esencia.

Esta afirmación general se debe ver en perspectiva considerando la posibilidad de que las mismas no tengan dicha característica en algunos casos, pero es un lugar común, al menos desde Kelsen, que las normas jurídicas, además de órdenes y coactividad producen derechos y obligaciones donde las mismas nacen de la estructura lógica de las normas jurídicas. 
El Orden Jurídico incluye el Orden Jurídico Internacional y nacional y aquel se encuentra en un plano de autoridad y superioridad respecto de los Órdenes Jurídicos Privados, transnacionales o internacionales de corte privado y nacionales debido a que regulan aspectos fundamentales de la vida jurídica de tales sujetos de Derecho Internacional Público, sin los cuales los mismos sujetos no tendrían vigencia y existencia. Se analizan las "fuentes" del "Estado de Derecho Internacional Público" como Orden Jurídico. Esto supone relaciones entre sujetos de Derecho Internacional Público en igualdad jurídica. Un ejemplo, la ausencia de regulación jurídica internacional de las finanzas internacionales y la calificación como delito de las especulaciones de este tipo.

Es decir, no sólo se produce un efecto de auto-creación normativa sino de creación normativa por superioridad y autoridad y donde luego, en este "Estado de Derecho Internacional Público" sinónimo de Orden jurídico, se produce el proceso de producción, interpretación, aplicación y ejecución de las normas jurídicas internacionales.

\section{Origen del concepto}

En principio, este era un concepto anterior al de orden jurídico, era un concepto político relacionado con el balance entre orden y libertad (podría ser igualdad y libertad) pero en el Derecho Internacional Público lo proponemos como un conjunto de normas jurídicas cuya unidad, la norma jurídica internacional, establece derechos y obligaciones ${ }^{3}$. Hay dos grandes propuestas: la mexicana-lichtenstiana y la austriaca.

Este concepto político posee una serie de conceptualizaciones, en el mundo germánico, en el mundo anglosajón, en el mundo francófono y en el español así como en el iberoamericano ${ }^{4}$.

3 Este concepto adquiere desde diversas perspectivas un "status" jurídico, a saber, desde el momento en que se le considera como sinónimo de imperio de la ley o de otras opciones. Pero "Estado de Derecho" como conjunto de normas jurídicas dice relación a lo que es el orden jurídico, en esta investigación, y en anteriores textos, extraer los elementos propios del "Estado de Derecho nacional" para incorporarlo (o no) en un "Estado de Derecho Internacional Público".

4 El Estado de Derecho Internacional Público tiene como esencia un proceso de racionalización jurídico y otro político del Poder, en otras palabras, supone la fundamentación del poder. A su vez esta racionalización, un proceso de comprehension del poder y su fundamentación en el plano jurídico, dice relación con el fin de "seguridad jurídica”, que el Derecho aplicable sea homogéneo y cierto. Donde se difiere es en la forma de entender esta racionalización del poder, supuesto que el Derecho sea tal, es decir, poder. En el ámbito anglosajón supone que el Poder se somete al Derecho (el Poder político se somete al Orden jurídico). El soberano es el Parlamento o la Nación. "En el caso continental, la certeza y homogeneidad del Derecho llevan a un reajuste del sistema de fuentes, de modo que el derecho se convierte en la voluntad del poder soberano, que debe conformarse con las limitaciones impuestas en el pacto originario" Jaria i Manzano, J., La cuestión ambiental y la transformación de lo público, Tirant lo Blanch, Valencia 2011. En este caso el derecho es un conjunto de normas generales y abstractas donde se expresa la voluntad política de la comunidad constituida en Estado, fuente final en la medida en que tenga atribuido el monopolio del poder. Jaria i Manzano, Jordi, op. cit., p. 90. Los derechos se entienden positivizados y por consiguiente deben estar en el texto constitucional. Alvarez, A., Dissenting Opinion on the South West Africa Case, International Court of Justice. The Hague. Allí expresa un Nuevo Derecho internacional cuyas características nos llegan hasta hoy día. Vid. Peña Neira, S., "Hacia una fundamentación del Estado de Derecho Internacional”, en Becerra, M. y González, N. (eds.), Estado de Derecho Internacional, Universidad Nacional Autónoma de Mexico, Instituto de Investigaciones Jurídicas, 2012, pp. 129-194. 
Es dable señalar, sin embargo y de la mano de connotados internacionalistas y teóricos del derecho que este concepto tiene un fuerte desarrollo en la primera década del presente siglo 5 .

Expresa la necesidad de seguir aplicando normas jurídicas internacionales que han sido desarrolladas para alcanzar dicho "Estado de Derecho Internacional Público" de manera plena y que tiene por objeto orden jurídico, libertad política y económica y justicia social.

Pero es el primero de los elementos el más relevante. Es el que se considera esencial, el "Estado de Derecho Internacional Público" contiene normas jurídicas en un conjunto denominado Orden Normativo Jurídico Internacional donde existen fuentes de dichas normas y consiguientemente de dicho Estado que habrán de ser base para las normas de dicho Orden Normativo Jurídico Internacional y, además, luego de clarificar algunos conceptos y de definir su unidad "norma jurídica internacional" se estudia su relatividad y absolutismo, la relación con la Teoría General del Derecho, se debe analizar su aplicabilidad a nivel nacional, el que el Orden Normativo Jurídico Internacional es la expresión de una "Estado de Derecho Internacional Público", la aplicación como concepto diferente al de interpretación de normas jurídicas, la metodología jurídica en este "Estado de Derecho Internacional Público". Hoy día el espacio político-jurídico no sólo se concentra en un territorio sino en una serie de territorios del mundo.

\section{II.- "Fuente" y "expresión normativa", confusiones}

El Derecho Internacional Público posee fuentes u origen de sus normas jurídicas aunque el origen último sea único. El Derecho Internacional Público tiene como elemento esencial, del mismo modo que el Derecho en general, a la norma jurídica, "norma jurídica internacional"6.

Así también es necesario, desde ya, indicar que las "fuentes" del Derecho Internacional Público, son "fuentes" y "expresión normativa o norma jurídica" a la vez, planteándose, del mismo modo y como "fuente" la existencia de un Orden Normativo Jurídico Internacional, consecuencia de una "constitución" y que es "el conjunto de normas de derecho internacional que regulan la creación del derecho internacional”, son fuentes

Basta revisar las compilaciones de documentos de derecho internacional donde se deja constancia de la efectividad del Derecho Internacional Público aunque ya se observa la misma efectividad en el caso Nicaragua. Solo a vía de ejemplo en la doctrina Brownlie, I., Basic documents in international law, fifth edition, Oxford University Press, Oxford, 2002; Evans, M., International Law Documents, 8th Edition, Oxford University Press, Oxford, 2007; Dixon, Martin, McQuorquodale, R., Cases and Materials on international law, Oxford University Press, Oxford, 2003.

6 Kelsen, H., Teoría Pura del Derecho, Segunda traducción, Collihue, 2011, p. 59 y ss. Schmidt Assman, E., La Administración Europea por las Agencias Europeas, Cracovia, 2011 (Traducción al castellano, Peña Neira, S., en curso).

Al respecto, Kelsen, H., Principios de Derecho internacional público (Traducción Caminos, Hugo y Hermida, Ernesto), Ateneo, Buenos Aires, p. 259. 
de producción del derecho ${ }^{8}$, o sea, sus "fuentes" y que, al mismo tiempo, son parte de dicho Orden Normativo Jurídico Internacional, constituyendo éste el "Estado de Derecho Internacional Público".

\section{De la producción de normas a la ejecución de las mismas}

La producción jurídica es un presupuesto conceptual de la doctrina de la división de los poderes, del Orden Normativo Jurídico Internacional, del Derecho Internacional Público y del "Estado de Derecho Internacional Público".

La producción del derecho se genera sobre la base de las fuentes del Derecho, formales o materiales pero siempre fuentes de producción del Derecho.

La interpretación del Derecho supone la determinación del sentido y alcance de la norma jurídica a través de los enunciados jurídicos en que la norma de derecho se expresa y que pueden o no ser frases normativas ${ }^{9}$.

La aplicación del derecho implica la "actividad consistente en crear preceptos singulares y concretos de conformidad con normas (generales y/o abstractas) preconstituidas" ${ }^{10}$.

Finalmente la ejecución del Derecho "designa todo comportamiento material que constituya obediencia a una norma (que no esté dirigida a los ciudadanos privados sino a los órganos del Estado)"11.

Estas distinciones son relevantes para la producción, las normas jurídicas internacionales se generan por medio de fuentes formales, principalmente, con el objeto de regular relaciones jurídicas internacionales y nacionales al tener que interpretarlas y aplicarlas internacionalmente y nacionalmente (cuando corresponda y de acuerdo a la naturaleza de la norma jurídica internacional) y luego ejecutarlas ${ }^{12}$.

Esto se ha presentado, como lo explicó el profesor y Juez de la Corte Internacional de Justicia Antonio Cancado Trindade, en el caso "Baena Ricardo y otros vs. Panamá" de 22 de febrero de $2011^{13}$, una cuestión reiterada en el Derecho Internacional Público

Guastini, Ricardo, Distinguiendo, Gedisa, Barcelona, 1999, p. 81 y ss.

9 Las primeras serían las "proposiciones normativas interpretadas prescriptivamente" y, las segundas, son "descripciones realizadas por los juristas de una o varias normas". Capella, Juan Ramón, Elementos de análisis jurídico, Trotta, Barcelona, 1990, p. 62.

10 Guastini, Ricardo, op. cit., p. 83.

11 Guastini, Ricardo, op. cit., p. 83.

12 Hay que hacer presente que la aplicación es discrecional salvo que la norma a aplicar no predetermine completamente el contenido del precepto singular, como es el caso de las normas de Derecho internacional de los Derecho humanos o el caso del Derecho internacional del Medio Ambiente, o predeterminada cuando se determina de manera definitiva el contenido del precepto "singular y concreto que desciende de ella". Guastini, Ricardo, op. cit., p. 84. Debemos recordar que tradicionalmente la aplicación se efectúa por un procedimiento silogístico.

13 Cancado Trindade, Antonio Augusto, Apuntes de clases del Programa de Derecho Internacional Público de la Academia de La Haya, Santiago, 2011. Con esta sentencia se deja de lado la noción de ser la jurisdicción sólo un proceso doble, conocimiento y juzgamiento, para pasar a uno triple, conocimiento, juzgamiento y aplicación y 
desde siempre, la norma, su aplicación primaria a nivel internacional y nacional y su aplicación secundaria a nivel nacional más su ejecución. Esta distinción, como la hemos indicado, es fundamental en el Derecho Internacional Público.

\section{Fuentes formales y materiales, consecuencias}

En Derecho Internacional Público no se hace una distinción entre fuentes formales, las normas jurídicas productoras de otras normas (normas secundarias en Hart) y las fuentes materiales del derecho internacional (hechos o actos que generan el Derecho) ${ }^{14}$. Las fuentes formales son, a la vez, normas jurídicas, regulando la creación normativa y, a la vez, siendo normas jurídicas obligatorias. El tratado internacional no sólo contiene derechos y obligaciones entre Estados sino que es en sí mismo una norma jurídica.

En este caso es posible hablar de "fuente de producción del Derecho" internacional público. Esta fuente de producción puede ser material ("identificar ciertos actos (y hechos) como fuentes del derecho independientemente de su contenido (o resultado)") y material ("pretende identificar ciertos actos (y hechos) como fuentes del derecho independientemente de su contenido (o resultado)" $)^{15}$.

Esta distinción de Teoría General del Derecho o Teoría del Derecho no se efectúa en el Derecho internacional con lo cual, como es obvio, se genera una confusión respecto de fuentes que pierden forma y fondo, es decir, son fuentes materiales del Derecho pero no se encuentran formalizadas, pueden o generan derechos y obligaciones ex novo sin contar con un origen, permiso, vigencia (puede tratarse de soft law o de ius cogens aunque no es completamente clara esta posibilidad).

A su vez, el concepto "material" de fuente es un concepto teórico material que pretende determinar cuáles son las fuentes de cada Orden Normativo Jurídico Internacional, en este caso internacional, de un modo independiente del contenido positivo del Orden Normativo Jurídico Internacional en cuestión. De otra parte, el concepto "formal" es un concepto "dogmático" a fin de determinar las fuentes de un orden a través del contenido positivo del Orden en cuestión (normas sobre producción jurídica) ${ }^{16}$ en este caso, el artículo 38 del Estatuto de la Corte Internacional de Justicia.

La noción material supone la creación de normas generales y abstractas nuevas con lo cual se modifica el Orden Normativo Jurídico Internacional de hecho, es decir, cualquier acto o hecho que modifica el Orden Normativo Jurídico Internacional ${ }^{17}$. Se mira a la sustancia, no a la forma, y se estudia el contenido del acto para determinar si

\footnotetext{
se abandona dicha opción que al menos entre nosotros mantuvo el gran profesor uruguayo D. Eduardo Couture y que ha sido seguida por una parte importante de los procesalistas.

14 Guastini, Ricardo, op. cit., p. 81 y ss.

Guastini, Ricardo, op. cit., p. 81.

Guastini, Ricardo, op. cit., pp. 81-82.

Guastini, Ricardo, op. cit., p. 83 .
} 
es fuente del derecho, lo que puede generar, en principio, un problema de inseguridad jurídica al no determinarse una norma general y abstracta.

\section{El tratamiento en el Derecho Internacional Público}

Incluyen los tratadistas a fuentes formales que, en realidad, son materiales o que no son fuentes; entre las primeras, por ejemplo, podríamos incluir a la Equidad o al "ius cogens", la Justicia, el denominado "soft law", y entre las segundas el "soft law", las resoluciones de la Asamblea General de las Naciones Unidas o del Consejo de Seguridad de la misma organización.

En el caso del Derecho Internacional Público hablamos de "norma jurídica internacional", que posee, aunque a veces pueda no creerse, características especiales que enriquecerán la Teoría general del Derecho en lo que se refiere a las normas jurídicas ${ }^{18}$.

\section{III.- Definición de "norma jurídica internacional”}

La "norma jurídica internacional" tiene, como fuente, una serie de expresiones, y podemos consignar dos, las más importantes, a saber, tratado y costumbre ${ }^{19}$. Pero no son las únicas, está presente la doctrina, la jurisprudencia y los principios generales del derecho así como la equidad y la voluntad unilateral de los Estados y otras.

En el caso del Derecho Internacional Público hablamos de "norma jurídica internacional”: una estructura lógica que debe incorporar la aplicación desde el Derecho internacional al Derecho nacional como una obligación, supuesta su aplicabilidad, la que puede ser directa, determinada por la Constitución política de cada país o, finalmente, la generación directa de una norma jurídica nacional, copia y adaptación de la norma jurídica internacional o indirecta, supuesta la ratificación del Estado a la norma jurídica internacional. Otro requisito es que la fuente del Derecho de que se trate sea aplicable o que la misma norma jurídica internacional sea aplicable porque habrá de establecer normas jurídicas a personas naturales y personas jurídicas en relación al Estado en cuyo territorio y jurisdicción se aplican.

Las primeras nombradas, tratado y costumbre, se encuentran en el artículo 38 del Estatuto de la Corte Internacional de Justicia. Este Estatuto posee efecto vinculante para quienes se someten a su competencia y es considerado la fuente primaria de las

18 Al respecto es necesario mencionar que las normas jurídicas internacionales reúnen las características lógicas de la norma jurídica en general expresadas en el sencillo "Si es A entonces B; si no es B entonces C". Las normas jurídicas internacionales agregan elementos relacionados con otros aspectos relevantes, es el caso de la forma en que la sanción toma forma, la interpretación de las mismas que puede ser doble, es decir, puede ser interpretada como propia de las relaciones interestatales o en la aplicación a nivel nacional, generando, a su vez, la necesidad de ser reinterpretadas a nivel nacional.

$19 \mathrm{Al}$ respecto, Kelsen, Hans, op. cit., p. XII. 
fuentes normativo-jurídicas internacionales o del Derecho Internacional Público ${ }^{20}$. La Convención o el tratado son fuente o creación del Derecho o aplicación del mismo, dependiendo de la situación jurídica de que se trate ${ }^{21}$. Esta regla de derecho o afirmación normativa es aplicable a la costumbre jurídica internacional. Sin embargo, hemos visto que el Derecho Internacional Público se mueve, respecto de ambas, costumbre y Derecho, entre la relatividad y el absolutismo.

\section{V.- Bello, Álvarez y el Estado de Derecho Internacional Público diversos tribunales como el tribunal de presas en materia de fuente de las fuentes formales de Derecho Internacional Público}

La noción de Orden Normativo Jurídico Internacional a fin de solucionar conflictos entre sujetos de Derecho Internacional Público no es nueva sino que tiene entre sus propugnadores a pensadores lationamericanos como Bello o Álvarez dado que sin ellos buena parte de las formas pacíficas de solución de controversias en Latinoamérica no hubiere sido posible o la existencia de la Declaración Universal de los Derechos humanos y de una serie de derechos no tendría vigencia.

Don Andrés Bello indicó en sus "Principios de Derecho Internacional Público" que el origen de sus disquisiciones sobre el tema jurídico internacional tenían como base un Orden que provenía de la razón y de un creador ${ }^{22}$. Dice Bello:

"Toda ley supone una AUTORIDAD de que emana. Como las naciones no dependen unas de otras, las leyes o reglas á que debe sujetarse su conducta recíproca, sólo pueden serle dictadas por la razón, que a la luz de la experiencia, y consultando el bien común, las deduce del encadenamiento de causas y efectos, que ha dado al hombre un irresistible conato al bien ó a la felicidad, y no nos permite sacrificar la ajena a la nuestra, es por consiguiente el verdadero autor de estas leyes, y la razón no hace más que interpretarla." ${ }^{23}$.

Sitúa entonces nuestro autor como fuente material de las normas al Creador y al razonamiento. Claramente, en un orden deductivo de corte normativo.

Agrega el profesor Bello:

20 Son las denominadas fuentes formales del Derecho Internacional Público.

${ }^{21}$ Kelsen, H., El contrato y el Tratado (analizados desde el punto de vista de la teoría pura del derecho), Ediciones Coyoacán, Primera edición, 2007.

22 Bello, A., Principios de Derecho internacional público, Segunda edición aumentada y corregida por el autor, Librería de Garnier Hermanos, París, 1864, p. 12. Dice expresamente que el Derecho internacional

“(...) o de Gentes es la colección de las leyes o reglas generales de conducta que las naciones o Estados deben observar entre sí para seguridad y bienestar común.”

Leyes se considera como reglas generales de conductas entre naciones o Estados.

23 Bello, Andrés, op.cit., p., 12. 
"El Derecho internacional o de Gentes no es pues otra cosa que el Natural, que aplicado á las naciones, considera al género humano, esparcido sobre la faz de la tierra, como una gran sociedad de que cada cual de ellas es miembro, y en que las unas respecto de las otras tienen los mismos deberes que los individuos de la especie humana entre sí." ${ }^{24}$.

Refuerza las nociones de Orden Normativo Jurídico Internacional sobre la base de un derecho racional que considera tanto la razón como a un ser sobrenatural como fuentes materiales. Inclusive, asocia a la ley, leamos norma, una sanción, deduciendo diferentes sanciones y en el caso de lo internacional, la "vindicta humana".

Nuevamente se expresa la noción de orden cuando define derecho con dos sentidos, "colección o cuerpo de leyes" o "facultad de exigir que otro ejecute, omita o tolere algún acto" ${ }^{25}$, siendo en el primero de los sentidos en el que se encuentra el marco de lo dicho como Fuente material del Derecho internacional o de Gentes, del mismo modo que las dos definiciones que se entregan de Derecho internacional o de Gentes, es decir, colección o cuerpo de leyes u Orden Normativo Jurídico Internacional, al cual en este trabajo se le ha dado el nombre de Estado de Derecho Internacional Público.

Derecho en el segundo sentido supone obligaciones fundadas en la evidencia que de una facultad que exige una prestación hay un deber de poder exigir tal prestación. Entonces tal Orden Normativo Jurídico Internacional se constituye de Derechos y obligaciones.

Suponemos que el Estado de Derecho Internacional Público como Orden Normativo Jurídico Internacional a fin de organizar el Derecho Internacional Público y su estructura normativa bajo el imperio de la Norma jurídica internacional. Si se interpreta la Norma jurídica internacional vis a vis otras normas jurídicas internacionales debería interpretarse en relación a otras normas jurídicas internacionales de modo armónico considerando que las mismas son parte de un Orden Normativo Jurídico Internacional.

\section{VI.- Relatividad y absolutismo de las fuentes del Derecho internacional $^{26}$}

Las fuentes del Derecho Internacional Público se han relativizado o absolutizado dependiendo del respectivo punto de vista que tomemos.

La relativización se inicia con la noción de "soft law" (aun antes, con el concepto de "lege ferenda”) y el intento de descubrir una norma jurídica en las expresiones de voluntad

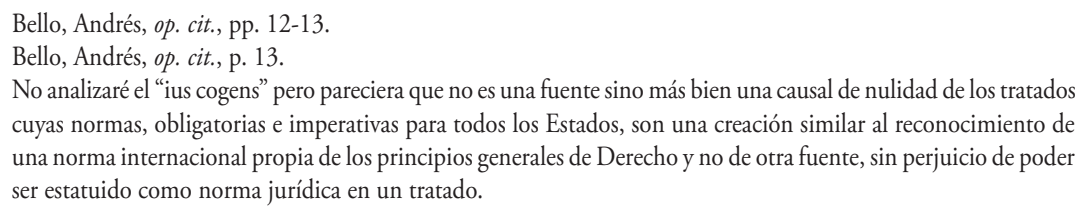


de la Asamblea General de la Organización de Naciones Unidas, en las declaraciones internacionales y otros actos humanos cuyo valor jurídico se encuentra en discusión.

Tales concepciones se enfrentan a la noción de Derecho sancionado, cuando procede de alguna de las fuentes del Derecho Internacional Público, ya nombradas, Tratados y Costumbre jurídica internacional.

Estas nociones vienen de alguna manera a provocar problemas en el Orden Normativo Jurídico Internacional y, a la vez, a provocar dificultades de comprensión debido a lo transitorio y carente de seguridad jurídica de sus fundamentos jurídicos. Lo anterior afecta su aplicación desde el ámbito internacional al nacional ${ }^{27-28}$.

\section{VII.- Las fuentes del Derecho Internacional Público y su relación con la Teoría General del Derecho, verbo y sustantivo}

En el Derecho Internacional Público nunca habrá de escatimarse importancia al tema de las fuentes. Junto con la norma jurídica internacional, el Orden Normativo Jurídico Internacional (que entendemos engloba al internacional y nacional), las fuentes representan un tercer sector de responsabilidad vital para el Derecho.

Si como proponemos, el Orden Normativo Jurídico Internacional es uno, entonces las fuentes serán únicas y, si las fuentes son únicas, entonces cuáles son las mismas: La respuesta es: las fuentes del Derecho internacional al cual el Derecho se debe.

He leído el que la noción de que la aplicación de una norma jurídica internacional es algo así como una "ideología"29. La inmensa mayoría si no la unanimidad de la doctrina ha planteado que esa es una obligación y esto es de tal nivel que algo similar ha concluido la Comunidad internacional al aprobar la "Convención de Viena sobre Derecho de los Tratados", con lo cual estamos frente a un incumplimiento de una obligación internacional por ausencia de una ejecución de la obligación de manera exacta. Ergo, no se trata de una ideología sino de una realidad.

Las fuentes del Derecho internacional de carácter formal son las que entregan los fundamentos para el desarrollo del Derecho Internacional Público.

27 Además, parecería que un nuevo grupo de fuentes, las internacionales, se superpone a las nacionales. Es en este contexto que es necesario encontrar solución a la aplicación posterior a la interpretación, de las normas jurídicas internacionales en el plano nacional. Este tema es aun más complejo derivada su complejidad del concepto de principios generales del Derecho del Artículo 38 número 1 del Estatuto de la Corte Internacional de Justicia. Además de la definición de este concepto, parecería, como lo indica Friedmann, que es posible a través del mismo, como obligación internacional de utilizar dicha fuente en la interpretación del Derecho Internacional Público, como medio para la incorporación de normas jurídicas que tengan la posibilidad de ser aplicadas en el Derecho nacional bajo estos conceptos.

28 Friedmann, W., La nueva estructura del derecho internacional, Trillas, 1967, p. 216.

29 Aldunate, E., "La posición de los tratados internacionales en el sistema de fuentes del orden jurídico chileno a la luz del Derecho positivo, Ius et Praxis, № 2, Ańo 16, 2010, pp. 185-210. Opiniones que no sólo no comparto en relación a la relación Derecho Internacional Público y Derecho nacional por pertenecer a un mismo Orden jurídico. 
Aun así posee una doble existencia o un doble sentido, así puede ser un título o calidad o la realidad incorporada en una norma jurídica.

En efecto, es sustantivo en cuanto una "fuente", por ejemplo, un tratado, es tal por encontrarse en el artículo referido del Estatuto de la Corte, pero además por poseer la calidad de tal debido a que genera derechos y obligaciones. Además, en el caso de nuevas posibles "fuentes", poseen la calidad pero no el título, al menos, en lo que aparece en el Estatuto referido.

Esto conlleva que todo Orden Jurídico tendrá una serie de fuentes formales pero las mismas fuentes pueden ser tanto títulos como aquellas que tengan la calidad.

\section{VIII.- Las “fuentes" del Derecho Internacional Público en el Derecho nacional}

Las fuentes del Derecho Internacional Público en su aplicación nacional muestran serias diferencias basadas en su propia naturaleza aunque en principio, por una cuestión de lógica, no exista diferencia ${ }^{30}$. Es decir, potencialmente pueden ser aplicables todas en el Derecho nacional aunque, sin duda, habrá algunas de aplicación jurídica más conveniente o menos conveniente dada su precisión ${ }^{31}$.

\section{Aspectos teóricos}

Desde el punto de vista teórico no hay razón para pensar que no se puedan aplicar las fuentes del Derecho Internacional Público en el Derecho nacional. Si miramos al Orden Normativo Jurídico Internacional como un todo observamos que el mismo es, sin duda, depositario de las normas jurídicas internacionales que tienen su fuente y su expresión en las denominadas "fuentes del Derecho Internacional Público".

Sin embargo, la pregunta que se debe formular es si, de acuerdo a la naturaleza de las normas jurídicas internacionales expresadas en las fuentes indicadas, son aplicables (o no) en el Derecho nacional.

En el caso de los tratados, salvo que se refieran exclusivamente a derechos y obligaciones entre Estados, tienen aplicación interna a través de la generación de derechos (y la consiguiente obligación) de los sujetos de Derecho nacional vis a vis el Estado.

Kelsen, Hans, op. cit., p. 348.

Es necesario indicar que al ser aplicadas las normas jurídicas nacionales conceden derechos y obligaciones a los gobernados, es decir, a quienes son los objetos de la norma internacional que devienen en una situación jurídica diferente, sujetos de derecho nacional, supuesto que no se trata de normas jurídicas internacionales reguladoras estrictas de relaciones interestatales y que sea posible de ser aplicada a nivel nacional. 
En el caso de la costumbre internacional de carácter público, cuando es la creación de una norma jurídica internacional estrictamente interestatal, la posibilidad de su aplicación resulta difícil a nivel nacional.

La tercera fuente del Derecho Internacional Público que podemos nombrar y que puede generar normas jurídicas internacionales son los denominados principios de Derecho Internacional Público, dado que los mismos pueden ser aplicables a nivel nacional pero supuesto que pueden generar derechos y obligaciones ${ }^{32}$.

Una cuestión es que se enuncie un principio, o varios como lo señala Kelsen, en orden a ser directivas simples para que podamos entendernos, otra es que se enuncien en orden a convertirse en directivas normativo-jurídicas y una tercera es la enunciación por parte de tribunales u órganos internacionales y su incorporación en tratados internacionales; en todos aquellos casos, la situación jurídica, su naturaleza, es diferente.

La jurisprudencia internacional, los fallos de tribunales internacionales no parecen posible de incorporarse a la legislación chilena salvo en cuento el Estado de Chile deba cumplirlos de manera directa pagando alguna indemnización de perjuicios o provoquen la modificación de normas jurídicas que tengan como fuente el Derecho nacional.

La doctrina de los más connotados internacionalistas, salvo que se falle incluyendo tales doctrinas en el fallo. Pues bien, resulta difícil que encontremos tal actividad dentro de los fallos de nuestros tribunales que, incluyendo al Tribunal Constitucional, fallan aplicando criterios jurídicos nacionales rechazando fuentes de Derecho Internacional Público y desarrollando un fuerte criterio antagónico a la aplicación de normas jurídicas con fuentes de Derecho internacional.

\section{Aspectos prácticos (aceptación y rechazo)}

Es por lo anterior que es dable afirmar el rechazo de las normas jurídicas internacionales o su aplicación incorrecta debido a una interpretación incorrecta a la misma.

En este sentido debemos mirar al Orden Normativo Jurídico Internacional y las fuentes.

\section{IX.- El Orden Normativo Jurídico Internacional como expresión del "Estado de Derecho Internacional Público" en relación a las Fuentes del Derecho}

Este "Estado de Derecho Internacional Público" tiene como expresión el Orden Normativo Jurídico Internacional en su globalidad y esto por cuanto existe una pri-

32 La referencia a "naciones civilizadas" ha quedado excluida dado que hoy día a todos los Estados se les considera "civilizados". 
macía de parte de este Orden Normativo Jurídico Internacional dejando de lado a los Ordenamientos Jurídicos Nacionales.

A diferencia de lo que en algunos casos se promueve, una suerte de ideologización de la aplicación de las normas jurídicas internacionales en el Orden Jurídico Nacional, este planteamiento supone que las normas jurídicas internacionales tienen plena aplicación debido a su pertenencia a un Orden Jurídico único con expresiones diferentes a nivel internacional y nacional y con fuentes que si bien son diferentes en varios casos son fuentes tanto a nivel internacional como a nivel nacional.

Un tratado ratificado por un país (sin perjuicio del supuesto del artículo 5 inciso 2) siempre será de aplicación directa a nivel nacional debido a que si entrega derechos y obligaciones a sujetos de Derecho nacionales o es el Estado el depositario del deber de velar por dicho derecho, no cabe duda que asumirá el deber de hacer efectivos los derechos de tales sujetos de Derecho como también sus deberes.

\section{X.- La aplicación como diferente a la interpretación de las normas jurídicas internacionales en un Orden Normativo Jurídico Internacional como expresión del "Estado de Derecho Internacional Público"}

El "Estado de Derecho Internacional Público" tiene diferentes momentos entre la interpretación de una norma y su aplicación.

Toda norma jurídica, prístina inclusive, sufre un proceso de interpretación ${ }^{33}$.

Luego tal proceso deviene en uno de aplicación. El primero, en un "Estado de Derecho Internacional Público", supuesta la existencia de una norma jurídica de carácter formal expresada en un tratado, supone la determinación de la descripción del tipo contenida en la misma, su determinación de sujetos a los que se les debe aplicar y el objeto de aplicación.

Una fase diferente, tras este primer momento, es el de determinación de la forma de aplicación dado el caso concreto, el ámbito específico donde es aplicable la norma.

\section{XI.- La metodología del Derecho Internacional Público supuesta la pluralidad de fuentes}

Siempre aparecerá, sin embargo, un problema, el de la metodología del Derecho internacional, supuesto que opera entre sujetos, en primera instancia, diferentes, es decir, sujetos internacionales y luego nacionales, para luego encontrarnos con objetos

33 Guastini, R., Teoría e ideología de la interpretación constitucional, Mínima, Trotta, 2007. 
diferentes, las relaciones jurídicas entre los Estados y luego la de los Estados con sujetos u objetos nacionales, según sea posible.

Además es necesario comprender que existe una pluralidad de fuentes y de formas en que las mismas habrán de aplicarse a fin de configurar la norma jurídica de que se trate, en el proceso de interpretación o proceso interpretativo correspondiente y luego ver el proceso de aplicación mismo.

\section{XII.- Conclusión}

El "Estado de Derecho Internacional Público" es un nuevo concepto que puede o no tener una fuente en normativas externas a las fuentes del Derecho Internacional Público, asimilables a principios generales del derecho, costumbre internacional o doctrina internacional.

Siendo un nuevo concepto se considera aquí en una perspectiva jurídica y dogmática a fin de que sistemáticamente se pueda incorporar a dicho concepto elementos del Derecho Internacional Público. En este sentido la disciplina es una, el Derecho Internacional Público, otro es este nuevo concepto que permea y establece una interpretación del sistema internacional como Orden Normativo Jurídico Internacional.

El "Estado de Derecho Internacional Público" cambia de un concepto de corte político a uno jurídico.

El concepto jurídico de "Estado de Derecho Internacional Público" supondría estudiar lo que es un Estado de Derecho, sus características, elementos para luego incorporarlos a la caracterización de un Estado de Derecho internacional. Esto bajo el supuesto que un "Estado de Derecho Internacional Público" será, sin duda, un Orden Normativo Jurídico Internacional.

Este Orden Normativo Jurídico Internacional que abarca al Orden Jurídico Nacional tiene una unidad, la norma jurídica internacional cuya estructura (no abordada en este texto por latitud) posee características especiales desde el punto de vista lógico pero que al igual que cualquier otra norma jurídica establece derechos y obligaciones.

Existe una fuerte confusión de "fuentes" en el Derecho Internacional Público, así no se distingue entre fuentes materiales y formales considerando al "Estado de Derecho Internacional Público" y las resoluciones que lo han establecido en la Asamblea General de Naciones Unidas, un concepto propio de las fuentes materiales, aunque la configuración final de las misma sea la de un Orden Jurídico.

Es posible que las "fuentes" del Derecho Internacional Público de carácter formal se puedan aplicar al Orden Jurídico Nacional, no cabe duda que las convenciones y los principios pueden aplicarse pero no así el resto de las fuentes. 
Hay autores en Latinoamérica que han insinuado un Orden Jurídico Internacional que es o puede ser un Estado de Derecho internacional, basando en el Derecho, el Orden Jurídico y las normas jurídicas las relaciones entre Estados.

Las fuentes del Derecho Internacional Público se crean, interpretan, aplican y ejecutan de forma integrada y sistemática cuando se entiende que el sistema internacional (comunidad o sociedad internacional) se rige bajo una noción jurídica de Estado de Derecho Internacional Público.

Finalmente, la interpretación y aplicación y ejecución de las normas las ejecutan los tribunales de justicia internacionales y nacionales pero desde perspectivas diferentes y buscando supuestos jurídicos, argumentos jurídicos, relaciones jurídicas procesales, que les permitan justificar y probar por medio de normas jurídicas, la competencia (dejo de lado el concepto de jurisdicción) en materia de juzgamiento de los conflictos internacionales.

Pero esto será motivo de ampliación y será tratado en otro momento. 